\title{
São Paulo de Ramos de Azevedo: da cidade colonial à cidade romântica
}

Janice Theodoro

Departamento de História, Faculdade de Filosofia, Letras e Ciências Humanas/Universidade de São Paulo
A cidade de São Paulo guardou por muitos séculos o seu perfil desenhado de acordo com o imaginário colonial. O casario não trazia as marcas da monumentalidade /característica de cidades como Salvador ou Rio de Janeirol, as casas não respeitavam normas de alinhamento, animais andavam soltos pela rua', o mato crescia em terrenos abandonados, e os formigueiros ${ }^{2}$ eram tema constante de crítica à política da Câmara, incapaz de transformar São Paulo numa cidade que agradasse ao "visitante europeu".

Iniciamos o século XIX, mais envolvidos em temas ligados à vida do campo do que da cidade. As transformações foram profundas a partir da segunda metade do século XIX e principalmente na primeira metade do século $X X^{3}$. A mudança não foi apenas quantitativa mas qualitativa.

$O$ século XIX representará, neste sentido, a passagem de uma cidade com uso e sociabilidade rurais para uma cidade capaz de gerenciar um novo tipo de relações sociais. A busca destes novos referenciais corresponderá às expectativas do homem moderno no Brasil. É interessante notar que o imaginário urbano se transforma antes das relações econômicas justificarem esta mudança. Ou seja, desejávamos um desenho de cidade semelhante ao europeu sem termos atrás de nós uma revolução industrial que justificasse estruturalmente a mudança. A nossa relação primeira era com a cena da modernidade. Neste sentido a chegada do imigrante terá um papel muito importante porque ele é o único que podia, com sua herança de artesão europeu, repetir com exatidão o modelo, incorporando-o à nova dinâmica da vida urbana paulistana.
1. Em 1850 foi apresentado à Comissão Permanente um projeto de postura que caracterizava, em detalhe, os novos padròes de uso e ocupaçāo do solo. Os artigos que mais diretamente se referem ao tema tratado acima são os seguintes: "Art. 3\%. Fica igualmente proibido nas três freguesias da cidade (Sé, Braz, e Santa Ifigênia) conservarse vagando pelas ruas $\mathrm{e}$ praças - cabras, e bem assim o costume de fazer brigar galos nos mesmos lugares. Contraventores incorrerão nas penas do art. $1^{\circ}$; Art. $4^{\circ}$. Fica proibida a criaçào de pombos e galinhas soltos pelas ruas e praças da freguesia de Sé, Santa Ifigênia e Brás. Os contraventores incorrerào em multa de 2 a $4 \$ 000$ rs".

2. En 1920 um Parecer da Comissāo de Justiça da Câmara decreta: "Art. 1‥ Fica a Prefeitura autorizada a reorganizar o serviço de extinção de 
formigueiros. Art. 2․ Este serviço deverá ser feito pelo sistema que for julgado mais conveniente, contratando o prefeito $O$ pessoal necessário. Art. $9^{o}$ Conhecida a existência de um formigueiro, deverá ser o proprietário do local intimado a extingui-lo no prazo de 48 horas. Se a intimação nào for cumprida ser-lhe-á imposta a multa de $50 \$ 000$ e o serviço será feito, a sua custa, pela Prefeitura".

3. Atas da Câmara, 15 de janeiro de 1914. "O desejo constante de transformar-se esta capital em uma cidade belíssima $\mathrm{e}$ higiênica, corrigindo os defeitos de antigos alinhamentos, abrindo-se largas avenidas e praças de modo a torná-la cheia de encantos e atrativos, o verdadeiro expoente deste rico e próspero Estado, levou a Câmara a convidar o notável engenheiro arquiteto francês $J$. Bouvard que se achava em trânsito para Buenos Aires, a dar a sua valiosa e respeitável opinião sobre os planos de melhoramentos estudados e formular um projeto a este respeito...".

4. A argüiçào à tese de Maria Cristina Wolff de Carvalho, A Arquitetura de Ramos de Azevedo, elaborada pela Profa Janice Theodoro, deu origem a este artigo,

5. Atas da Câmara de São Paulo, dia 26 de dezembro de 1914, intervençào de Carlos Botelho: "...nem a nossa civilização e nem o brilho e a elegância das ruas que constituem tão afamado
Muitas vezes tendemos a contrapor a cidade colonial à cidade romântica em função basicamente do desenvolvimento econômico. Atribuímos ao café a energia motivadora da mudança. Sem dúvida, o crescimento econômico influenciou as formas de vida e organização do espaço urbano na cidade de São Paulo. Mas, o que levou à quebra - de um padrão da urbanidade mestiça (urbana/rural) e à substituição por um outro padrão de urbanidade copiada - foi a mudança da mentalidade das elites brasileiras. Deixavam os elegantes salões para se dirigirem às escolas e universidades européias.

Eu diria que o café permitiu que os fazendeiros dessem mais substância à sua imaginação a partir de uma vivência escolarizada. A ruptura com o passado se constituiu a partir: 1) de uma fantasia estetizante de urbanidade, 2) de uma urbanidade regida por normas eficazes e 3/ de uma utopia técnicocientífica. Em suma, não eram poucos os argumentos iluminados que justificavam a ruptura com um passado marcado pelo atraso.

Um dos grandes responsáveis pela expressão visual da mudança na cidade de São Paulo foi Ramos de Azevedo (1851-1928)4. Sua biografia nos permite compreender como este arquiteto foi capaz de colocar no papel o sonho de muitos brasileiros ansiosos por assistir a transformações rápidas no desenho urbano. Era geral o desejo das elites de participar da modernidade no que ela tinha de mais exterior. Na Câmara discutia-se a pavimentação das ruas tendo como argumento central a roupa das damas que não poderiam ficar sujas de barro quando fossem assistir a uma corrida de cavalos. A presença de carruagens puxadas por animais era criticada porque deixavam a ruas marcadas pelos excrementos dos animais, os casarios baixos deveriam ser destruídos porque enfeiavam a cidade. Grande parte do desejo de mudanças era sustentada por argumentos que não possuíam uma raiz funcional. Ou seja, a modernidade era compreendida pela maior parte das elites brasileiras como um quadro na parede. Na Câmara, o que mais se discutia eram medidas de embelezamento. A cidade tinha que mudar sua vestimenta, deveria ter vitrines à moda européia ${ }^{5}$, edifícios altos, ruas pavimentadas etc., etc.

Embora a percepção das elites fosse estreita, Ramos de Azevedo sabia agradar indo bem além, buscando as raízes de um novo urbanismo. Neste sentido ele era um arquiteto cuja obra discutia com inteligência a possibilidade desta passagem. $O$ estilo estava adequado ao sonho sem que este interviesse na racionalidade do processo construtivo. Sem se fazer notar, resguardado por uma arquitetura aparentemente conservadora, o arquiteto se desvencilhava (em parte) de uma sociedade tradicional para penetrar no mundo da ciência moderna.

Ramos de Azevedo partiu em busca de um saber empírico, baseado na eficácia, na utilidade, do qual fez parte também uma relação original entre o artista e o seu público. Este é o espaço no qual foi constituída a obra de Ramos de Azevedo. A roupagem é marcada por um classicismo romântico mas a sua concepção arquitetônica está ancorada em uma racionalidade que inșitui um saber crítico ${ }^{6}$, indispensável para a constituição posterior do movimento moderno.

O desejo da ruptura

Em que medida a obra de Ramos de Azevedo expressa uma ruptura com o passado? 
A primeira impressão que temos ao olhar suas obras é que o autor separa o velho do novo. Ele expressa visualmente uma ruptura profunda com o passado. Nada em sua obra nos lembra a época colonial, uma vida comunitária, ou ainda, o mundo barroco. Seu compromisso explícito é com uma tradição européia muito em voga naquele momento e a sua brasilidade é invisível.

Visões parisienses da cidade presentes em seu desenho permanecem como um marco indicativo do que deveria ser a modernidade no Brasil. A cidade desejada no século XIX, não se parecia em nada com as cidades reais brasileiras. Portanto, substituir o novo pelo velho correspondia, em termos urbanísticos, a por fim aos edifícios velhos, baixos, sem portadas monumentais?, sem pedra, substituindoos por novos capazes de expressar a constituição de um novo cenário imponente adequado às transformações políticas e econômicas em curso na história brasileira.

Ramos de Azevedo estudou arquitetura na cidade de Gand (Bélgica) entre 1875 e 1878. Não apenas desfrutou de uma formação européia ${ }^{8}$ como filiou seu trabalho ao movimento arquitetônico europeu. Embora tenha passado apenas dois anos na cidade flamenga, a cultura européia foi uma constante na sua formação ainda quando estava no Brasil. Creio que este é um elemento que devemos destacar.

Os intelectuais brasileiros são intelectuais europeizados, especialmente quando estão em território brasileiro. As viagens representam basicamente a unção, uma espécie de rito de passagem. Estudar na Europa significava le creio que ainda significal a confirmação de tudo o que se tinha aprendido na outra margem do Atlântico. Se os professores europeus aprovavam, então estávamos diante de uma pessoa verdadeiramente inteligente que merecia o respeito dos brasileiros.

O fato de a Gazeta de Campinas publicar a notícia de que Ramos de Azevedo havia sido aprovado com distinção em Literatura francesa, Cálculo diferencial e integral, Mecânica racional, Geometria descritiva, Estereotomia, Arquitetura e Física comprova a nossa hipótese. Convém notar que a imprensa não notificou apenas uma vez os seus sucessos acadêmicos. Cada passo de Ramos de Azevedo na Europa era notícia. Ou seja, o seu sucesso em Gand fez parte da história da cidade e, de certa forma, onfunde-se com a história da família.

Esta visão eurocêntrica merece ser analisada porque antes de partir para a Europa o intelectual viveu em meio a uma sociedade diferente da européia. Não há, por exemplo, brasileiro no século XIX que não tenha desfrutado na sua infância uma relação intensa com a cozinha, com os criados e criadas, que não reconheça a importância das visitas, do quarto de hóspede e que não tenha um profundo fascínio pela sala de jantar, ou melhor dizendo, pela majestade da mesa. Ramos de Azevedo não se furtou à tarefa de pensar criticamente todos estes elementos procurando integrá-los de maneira harmônica no seu projeto.

Para ele não se tratava de negar as tradições mas realocar as antigas necessidadès do cidadão em edifícios privados e públicos, analisando o espaço para definir os novos pressupostos cognitivos. Ou seja, a análise da obra de Ramos de Azevedo exige que consideremos, para além do estilo, os princípios triângulo da cidade, não permitem mais certas práticas velhas e deselegantes. Se nas ruas 25 de março, Joào Alfredo e ladeira Sâo Joào etc. achamos pitoresco aspecto a exposição de fazendas às portas das casas de negócios (...) na rua 15 de novembro, onde os armazéns já nào são tão modestos como os das ruas acima mencionadas, onde é de uso vitrines elegantes, iluminadas a giorno, choca encontrar algumas peças atravancando a sua entrada, saindo umas para o passeio e outras dependurando-se como chamarisco. Acho que os negociantes das primeiras ruas citadas têm o direito de assim proceder visto como thes cabe uma freguesia menos exigente, de par a costumes e hábitos mais modestos. Mas aqui no triângulo, o estado de progresso, de adiantamento e civilização, exigem práticas mais européias, mais de acordo com a nossa atualidade elegante."

6. Sérgio Paulo Rouanet em seu livro Malestar da modernidade (1993), analisa o processo de ruptura com antigas cosmovisôes.

7. Anais da Câmara Municipal, 1912. Parecer no 43 da Comissão de Obras: “(..) entende a Câmara que não deve permitir nesta rua construçōes com menos de 3 andares, sendo que as fachadas devem ser aprovadas pela Prefeitura. Simultaneamente, pede o Sr. Prefeito a 
aprovaçào da planta no que diz respeito ao prolongamento das ruas Conselheiro Nébias, Barão de Limeira e Barào de Campinas até a rua São João, formando este prolongamento, no encontro com a rua Sào João três praças. (...) $\mathrm{O}$ Sr. diretor entende que a simples inspeção da planta da cidade mostra a importancia capital das duas artérias, São João e Palmeiras, ligadas à avenida paulista por meio de uma grande avenida projetada pela $S$. Paulo City Improuvements formando estas três artérias um circuito de passeio de que se orgulhariam muitas cidades do mundo".

8. Maria Cristina Wolff de Carvalho, em sua tese $A$ Arquitetura de Ramos de Azevedo, reconstrói em detalhe toda a formaçào européia de Ramos de Azevedo.

9. Um exemplo claro desse processo de estratificação são as praças "públicas". Elas não eram verdadeiramente "públicas" porque uma criança descalça não podia brincar no Jardim da Luz conforme atesta intervenção na Câmara de São Paulo, nas Atas de 1924: "com o aproveitamento cada vez mais intensivo dos terrenos.da zona urbana a situação da respectiva população infantil tende a agravar-se e urge uma providência (...). Ainda é possível encontrar mesmo nos bairros mais povoados, quarteiròes cujas partes internas podem ser dispostas sem grande sacrifício para o fim almejado. que nortearam a definição da planta do edifício e a sua inserção dentro de um determinado contexto urbano.

Do ponto de vista estilístico existe ruptura. Mas se analisarmos como foi concebido o edifício eu diria que Ramos de Azevedo, ao se defrontar com um projeto, refez um trajeto a partir dos ideais clássicos para colocar a questão da técnica. Ou seja, como bem demonstra Maria Cristina Wolff de Carvalho, na sua tese A Arquitetura de Ramos de Azevedo, os belgas (formadores de Ramos de Azevedol estavam mais preocupados em discutir qual o material adequado a uma necessidade do que em polemizar sobre o significado da forma arquitetônica. E é esta a visão, bem incorporada pelo aluno brasileiro, que passa a constituir um dos grandes eixos a partir dos quais Ramos de Azevedo vai definir o perfil do seu trabalho como arquiteto e do escritório o qual dirige.

Quando Ramos de Azevedo, por analogia, projeta residências semethantes àquelas desenhadas na Europa, ele absorve princípios básicos e processa a informação adequando-a à realidade na qual está inserido o edifício, objeto de seu projeto. Por exemplo, toda a discussão sobre salubridade para a qual o europeu despertava, tornava-se uma premissa para a qual ele estava muito atento. Ou seja, Ramos de Azevedo, para além do "estilo", absorve alguma coisa muito mais substantiva, incorpora a "razão" construtiva, os princípios que justificam aquele modelo de moradia privada ou aquele modelo de edifício público.

Portanto, a grande ruptura da obra de Ramos de Azevedo é com as "cosmovisões comunitárias" iá que ele pensa separadamente com dois modelos distintos, o público e o privado, fronteiras muito mal definidas nas cidades brasileiras. A tradição na sociedade brasileira era manter a diferença dentro de um mesmo espaço (casa grande e senzala são parte de um todo), enquanto que a sociedade moderna irá trabalhar com a estratificação do espaço $0^{\circ}$ Os projetos de Ramos de Azevedo envolveram a idéia de uma cidade estratificada que garantisse ao cidadão circulação eficiente. Ramos de Azevedo alcançou este objetivo? Não. Nem ele, nem ninguém. São Paulo, apesar de algumas tentativas de urbanização planejada, manterá a modernidade como uma espécie de esforço lítero-arquitetônico.

Esta é a ruptura que sua obra indica. Apesar dos esforços de Ramos de Azevedo e de sua geração, as mudanças serão apenas tópicas. No Brasil a passagem rumo a um universalismo foi constituida a partir de uma individualidade européia desfrutada apenas pela elite. A cidadania, portanto, constituía uma questão tipicamente francesa transplantada para o Brasil e indecifrável para o homem do campo que preferia ter proteção a ter liberdade. A casa pensada para este homem novo estava além das possibilidades reais da sociedade brasileira. Mas convém lembrar que a busca de Ramos de Azevedo é paradoxal na medida em que expõe estas ambigüidades. São Paulo não era e nem seria uma cidade semelhante a Paris apesar dos esforços dos arquitetos. A uma racionalidade construtiva se contrapõe uma sensibilidade conservadora bem adequada a um traço da sociedade brasileira. $\bigcirc$ "caos" urbano, resultado de uma sociedade onde o poder era profundamente fragmentado, tornava a definição de uma política urbana quase impossivel.

O que Ramos de Azevedo tinha atrás de si? Não era apenas a agradável, simpática e espaçosa casa colonial. Esta moradia exemplar era 
exceção, não regra. São Paulo foi uma cidade que lutou muito para alinhar as residências e para estabelecer regras mínimas de convivência entre aqueles que se tornavam vizinhos na urbe. Nas Atas da Câmara vemos referências a moradias construidas no meio da rua, loteamenłos onde o espaço privado foi concebido antes do público e à revelia dos interesses públicos, casas onde a salubridade nem se colocava como questão.

Portanto, Ramos de Azevedo partilhava da idéia, como outros homens de sua geração, de que a natureza humana é universal e que, inevitavelmente, caminhamos para um cosmopolitismo lele era essencialmente um homem cosmopolita). Para ele a questão da moradia ou da construção de um edifício para uso público estava baseada em cálculos, em uma administração racional do espaço, ou seja, numa mentalidade moderna. Fruto desta visão de mundo, Ramos de Azevedo desenvolve um projeto atrelado ao Estado já que esta rationalia só teria sentido, ou melhor, só conseguiria se impor mediante a intervenção planejada do Estado.

Como o trabalho de Ramos de Azevedo está em busca de uma razão ordenadora ele não se alicerça no passado brasileiro. Como a Europa the parece mais ordenada, provida de um urbanismo mais adequado às necessidades do mundo moderno e de formas mais harmônicas, ele postula a implementação deste modelo no Brasil. O que importa no caso não é a origem mas a razão prática que legitima o modelo.

Este foi o trajeto perseguido racionalmente por Ramos de Azevedo. Ele não está em busca de raízes. A questão que, hoje, se coloca ao analisar a obra de Ramos de Azevedo diz respeito ao princípio cognitivo com o qual ele trabalha e não à busca de uma brasilidade ou nacionalidade estilística.

Em busca da continuidade nosso passado?

A obra de Ramos de Azevedo expressa alguma continuidade com o

Eu diria que existe uma relação entre o princípio cognitivo que gerenciou parte da arquitetura colonial brasileira e aquele que sustentou a obra de Ramos de Azevedo, incorporado, posteriormente, pelo Movimento Moderno no Brasil. Só que este princípio é invisivel se considerarmos apenas o que é exterior nos seus edifícios. A visibilidade ocorre quando analisamos a lógica construtiva que norteou a arquitetura colonial brasileira transformada em razão construtiva no trabalho de Ramos de Azevedo.

Os portugueses e seus descendentes, ao chegarem ao Brasil, se viram obrigados a adaptar seus modelos construtivos à realidade brasileira, ao clima, à vegetação, ao relevo. $O$ homem foi capaz de abstrair e constituir um modelo a partir das suas necessidades mas não teorizou sobre ele.

Por que?

A sociedade colonial embora tenha em alguns momentos mantido processos de produção de conhecimentos esta percepção fragmentária só se constituiu como teoria na Europa. Neste sentido não existiu construção discursiva na América que desse continuidade a um saber original capaz de interferir explicitamente na organização espacial das cidades.
É a solução aconselhada por Aldridge. Além desses pequenos campos de jogos devem não perder de vista os terrenos de recreio das escolas públicas. (...) A eficácia desses espaços será grandemente aumentada se forem eles franqueados às crianças do mesmo bairro mesmo fora das horas escolares como é frequiente no Estados Unidos. Apesar da importância desse problema ele ainda é em São Paulo uma página em branco. Nenhum dos raros jardins públicos for preparado para atender a esta necessidade. (...) Esses jardins têm sido considerados somente como objeto de luxo e ornamentaçào; e até hoje o regulamento do Jardim da Luz veda a entrada às crianças descalças". 
10. O projeto de $n^{\underline{a}} 125$ apresentado à Câmara em 1912 caracteriza bem esta questào: “....Considerando que o Teatro Municipal é um monumento que honra a arquitetura brasileira e é justo orgulho dos paulistas, mas construído num espaço acanhado, que näo permite que sobressaia toda a sua importância e beleza arquitetônica e que devíamos, portanto, imitar a municipalidade de Paris, que não hesitou em demolir quarteirôes onde estava situada a grande Ópera, a fim , de dar maior realce ao monumento de Carlos Garnier".

11. Informação citada por Pablo Diener, grande especialista na obra de Rugendas.
A precariedade de recursos e técnicas, em uma área periférica como era São Paulo e Campinas, e a ausência de escolas que pensassem sistematicamente um projeto urbano brasileiro fez com que se fragmentasse 0 modelo de urbanismo colonial. Existem reflexões e debates sobre a questão urbana mas ela está centrada basicamente em modelos externos ${ }^{10}$.

Por que não foi possível conjugar a reflexão das nossas tradições com o pensamento europeu?

A dificuldade que se observa no século XIX em "ver" o Barroco, se justifica na medida em que a rationalia moderna precisou desacralizar as visões de mundo tradicionais para se constituir enquanto discurso (não enquanto conhecimento). Era necessário negar o passado. Ao mesmo tempo, no século XIX só se dispunha de discursos europeus para analisar os fenômenos urbanos que se tornavam inteligíveis pela Revolução Industrial. Esta transformação era basicamente européia e não brasileira.

Tomemos outro exemplo para confirmar a nossa hipótese. Rugendas pintou a América por vários ângulos. Viajou pelo México, Brasil, Chile, Argentina, dedicando-se a caracterizações detalhadas sobre a vida, os costumes e paisagens da América. Seguiu as pegadas de Humboldt, observador profundo da natureza americana. Mas na sua vastíssima obra não encontramos o barroco latino-americano"'. Portanto, o problema não era apenas de Ramos de Azevedo mas sim da consciência da época.

A leitura dos estilos arquitetônicos e do projeto em sua concepção mais ampla envolvia problemas de proporção, de construção, de técnica e de história européia na boa tradição greco-romana. Esta tradição em torno de uma reflexão teórica havia sido elaborada a partir da produção artística européia e, posteriormente, norte-americana. Portanto, o olhar sobre a problemática urbana se constituía a partir de uma perspectiva europeizante, onde os pressupostos estavam ancorados numa episteme clássica. Os textos da primeira metade do século XX e do final do século XIX correspondiam a um esforço comparativo com as cidadeș européias e norte-americanas e não a uma busca das nossas origens. $E$ significativa a discussão realizada na Câmara Municipal em 1924 sobre a remodelação da cidade:

“... a meses atrás cogitou-se em São Paulo a idéia de remodelação da cidade. Esta idéia foi acolhida, não só pelos poderes públicos estaduais e municipais, como também pelo público em geral (...). Nesta reunião no Palácio de Campos Elyseos foi solicitada pela municipalidade a organização de um plano conjunto de melhoramento da cidade.

Este plano já havia sido ideado por mim, nomeando uma Comissão composta dos competentes engenheiros Ulhôa Cintra, Prestes Maia, Gaspar Ricardo para coligir os estudos que houvesse na prefeitura e organizar todos, de modo a termos uma norma de trabalho eficiente e de grande resultado para a cidade.

(...) Por ocasião dos projetos do Teatro Municipal, ficou patente a curva de diagrama do crescimento de São Paulo, que só é comparável ao desenvolvimento de Chicago.

(...) Não só de terras do estado é, hoje, São Paulo a capital: a sua influência, tanto pelas iniciativas que partem, como pelas riquezas que afluem, transpôs as margens do Paraná e do Paranapanema, penetrou no norte paranaense e nas planícies infinitas de Mato Grosso, o mais digno cenário aberto à nossa atividade, e, talvez, em um futuro 
mais remoto um dos celeiros do mundo. Ainda mais: transpõe mesmo as fronteiras do país. Há entre São Paulo e o Paraguai, através de 1000 obstáculos, um comércio relativamente intenso, que nem todos conhecem. Os produtos da indústria paulista, depois de percorrerem toda a Sorocabana, descem do Porto Epitáfio, em demanda de Sete Quedas; ali transpõe por terra a catarata, para prosseguirem em seu curso, pelo baixo Paraná, até o ponto de desembarque de onde são levados para oeste, rumo de Assunção. É um fato que evidência as possibilidades de nossa indústria, dadas as facilidades muito maiores de comunicação que tem aquele país com o Prata. São Paulo, pela sua posição geográfica, pelas linhas que daqui irradiam, é a metrópole natural de uma imensa zona da América do Sul, que abrangerá, quiçá, com o tempo, outros países do centro e do oeste do continente. ( . . .

São Paulo marcha com passo mais rápido que o normal e de tal modo vai se distanciando das suas congêneres, deste e de outros continentes, que não pode subsistir dúvida de que ela está em uma fase decisiva da sua existência: a de sua passagem para o rol das grandes metrópoles.

O desenvolvimento da cidade foi muito lento a princípio e ainda é de ontem seu aspecto provinciano e atrasado...

(...) É de interesse geral do Estado, há uma conveniência coletiva na transformação e embelezamento da nossa capital, de acordo com um plano de conjunto, para que deixe ela de ser uma cidade provinciana e a transforme em um foco de atração e fixação para o estrangeiro, tendo em vista a previsão de seu futuro desenvolvimento e expansão, como centro comercial, bancário, industrial e ferroviário da mais rica, ativa e próspera região do Brasil.

(...) Nos Estados Unidos, quase todas as cidades, mesmo as mais modestas, organizam seus planos de remodelação e extensão. Elas bem compreenderam a significấncia do custo da confecção de um plano, diante da magnitude das economias que permitem realizar, evitando os passos em falso e as imprevidencias tão comuns na administração da cidade.

O valor do plano geral subsiste inteiramente, mesmo quando não há em vista grandes obras imediatas; não reside na grandiosidade ou na beleza dos projetos, mas na suavidade e conexão, e, sobretudo, neste seu caráter de obra de previsão que é inestimável".

No Brasil não haviam sido criadas escolas, ao longo de nossa história, que permitissem transformar em linguagem conceptual a arquitetura colonial brasileira. As escolas ${ }^{12}$ aqui podiam repetir o conhecimento nos moldes estruturados na Europa mas não podiam produzir conhecimento a partir das nossas ambigüidades históricas. Ou seja, o nosso patrimônio era constituído apenas por edifícios e cidades, sem uma consciência explicativa, sem um texto crítico, uma polêmica sobre eles. Teríamos que esperar a entrada em cena dos construtores do Movimento Moderno para que o Barroco pudesse ser resgatado no que tinha de essencial a partir de uma leitura que valorizava o que era autóctone.

Movimento Moderno toma consciência desse processo e se lança na produção de conhecimento à medida em que se transforma em linguagem. 0 primeiro passo é fazer do Barroco o nosso mito fundador onde está calcada a nossa ancestralidade. Para responder a este desafio constitui-se, contrapondo-se à estética neoclássica. A fundação exige diferença, diferença com a Europa e com todos projetos universalistas que não se definiam a partir de uma raiz
12. Em 1928, na Câmara de São Paulo é mencionada a questão da formaçào de urbanistas. A manifestaçăo a favor da criação de uma cadeira de urbanismo parte de Orlando Prado, que diz, em Ata clesse ano: "O urbanismo é hoje uma ciencia muito complexa que abrange grande número de conhecimentos. (...) uma escola Politécnica poderia prestar an mesmo municipio e ao Estado o inestimável serviço de preparar os urbanistas do futuro, os construtores das nossas grandes cidades do futuro". 
tupiniquim. Neste sentido a ruptura tornava-se um texto indispensável e a continuidade impensável.

A obra de Ramos de Azevedo representava tudo que tínhamos perdido ao considerar as necessidades dos homens iguais nos quatro cantos do mundo. O ecletismo e a falta de originalidade constituíram-se em argumentos centrais para os críticos. O maior pecado de Ramos de Azevedo foi partir de uma matriz transnacional, definindo claramente o espaço público e o privado, e priorizando o espírito científico como gerenciador da produção arquitetônica.

A identidade do Movimento Moderno encontrava sua razão de ser no nacionalismo e legitimava-se a partir de uma roupagem brasillica. Não éramos cidadãos do mundo mas coronéis encantados com as nossas cozinhas, varandas e natureza. A questão construtiva em Ramos de Azevedo precisava ser soterrada de forma a que ele e sua obra sobrevivessem na memória apenas como projetos de um burguês bem sucedido. Um arquiteto que, aparentemente, não teria deixado herança para a arquitetura brasileira. Grande engano.

Ramos de Azevedo produziu o elo subterrâneo entre o passado colonial e o Movimento Moderno. Para realizar a passagem, na aurora do século XX precisávamos do sacrifício de um construtor supostamente responsável pela presença de um imaginário europeu na América. Ele vestiu a fantasia, talhada com bom gosto, harmonia e equilíbrio /como diria um esteta grego ou renascentistal para manter vivas as tradições técnico-científicas às quais estava profundamente vinculado.

Se Ramos de Azevedo não era um iluminista era um iluminado!

Tanta coisa explicada, vale a pena lembrar que razão têm os poetas que dizem sem explicar (à moda de Carlos Drummond):

"fica sempre um pouço de tudo.

Ás vêzes um botão. Ás vêzes um rato."

\section{BIBLIOGRAFIA E FONTES CITADAS}

ATAS DA CÂMARA DE SÃO PAUlO. Publicação da Divisão do Arquivo Histórico do Departamento de Cultura da Prefeitura do Município de São Paulo. 2. ed. 1967. v. 1-66.

CARVAlHO, Maria Cristina Wolff de. A Arquitetura de Ramos de Azevedo. Tese (Doutorado). FAU/USP, 1996. 292 p.

LEMOS, Carlos Alberto Cerqueira. Ramos de Azevedo e seu escritório. São Paulo: Pini, 1993.

ROUANET, Sérgio Paulo. Mal-estar da modernidade. São Paulo: Companhia das Letras, 1993. 
Ouro Preto: from the transforming gestures of the "colonial" to the construction of the "modern antique"

Heliana Angotti Salgueiro

Urban and architectural changes experienced by XIXth-century cities allowed different sorts of cohabitation with the past and even the production of a "historic heritage". Different variables and their specific interplay are considered, such as, on the one hand, the cosmopolitan character of urban interventions and betterment projects, and, on the other hand, the introduction of new morphological, technico-constructive appliances or the transfer of models / both acting within a context of local material, political and cultural conditions. Ouro Preto, the mythical city is taken as a case study for understanding how efforts towards the construction of a "historical monument" artificially homogenized the urban reality to the disavantage of its historicity and actual transformations.

UNITERMS: Urban History. Historic heritage and lack of historicity. Ouro Preto.

Anais do Museu Paulista, N.Sér. v.4, p.125-63, jan./dez.1996

Bem-morar em São Paulo, 1886-1910: Ramos de Azevedo e os modelos europeus

\section{Maria Cristina Wolff de Carvalho}

A arquitetura doméstica tem um grande impulso no século XIX. Da Europa são difundidos, para todo mundo, os modelos conformados à nova ordem social e à industrialização. A residência se transforma numa preocupação central dos arquitetos. Desenvolvem-se novos conceitos para a casa ideal para todas as camadas sociais: operários, classe média, burguesia. Este artigo retraça, em São Paulo, a introdução de padrões formais e principios/de higiene, salubridade, conforto, ritos sociais e domésticos, as aparências), a partir da atividade de F. P. Ramos de Azevedo (1851-1920). Analisam-se os principais projetos que ele desenvolveu para a burguesia local.

UNITERMOS: São Paulo: arquitetura doméstica. História da Arquitetura. Ramos de Azevedo.

Anais do Museu Paulista, N.Sér. v.4, p.165-200, jan./dez.1996

The proper way of inhabiting, São Paulo (1886-1910): Ramos de Azevedo and the European models

\section{Maria Cristina Wolff de Carvalho}

Domestic architecture achieves a great impulse in the second half of XIXth-century. From Europe to the whole world, models are conformed to the new social order and spread as industrialization takes command. Dwelling becomes the main concern among architects. New concepts are developed for the ideal house for all social strata: working class, middle-class, bourgeoisie. This essay traces the introduction in São Paulo of European formal patterns and principles (hygiene, salubrity, comfort, social and domestic rites, social visibility) through the activity of F. P. Ramos de Azevedo (1851-1928). The main projects he conceived for the local bourgeoisie are analysed.

UNTTERMS: São Paulo: domestic architecture. History of Architecture. Ramos de Azevedo.

Anais do Museu Paulista, N.Sér. v.4, p.165-200, jan./dez.1996

São Paulo de Ramos de Azevedo: da cidade colonial à cidade romântica

Janice Theodoro

A A. analisa, a partir da atividade de Ramos de Azevedo, os elos implicitos entre o passado colonial de São Paulo e o movimento modernista e o papel desempenhado pelo imaginário europeu na América, assim como as tradições técno-científicas a que ele estava vinculado. 
Ramos de Azevedo's São Paulo: from the colonial city to the romantic city

Janice Theodoro

The A. analyses through the activity of Ramos de Azevedo the implicit links between São Paulo's colonial past and the Modernist Movement, and the role played by the European "imaginaire" in America, as well as the tecno-scientific traditions with wich he was affiliated.

UNITERMS: Urban History. History of Architecture. São Paulo. Ramos de Azevedo.

Anais Museu Paulista, N. Sér. v.4, p.201-8, jan./dez.1996

O Brasil vai a Paris em 1889: um lugar na Exposição Universal

Heloisa Barbuy

A A. estuda, de um ponto de vista museográfico, o significado da presença brasileira na Exposição Universal de Paris, de 1889. Com base em documentação rica e em grande parte ignorada ou pouco explorada, revela esforços empreendidos para apresentar o Brasil como um país atraente para estrangeiros e analisa o repertório alegórico mobilizado, juntamente com a retórica de diferentes tipos de exposições, sejam de produtos naturais, manufaturados, científicos ou artísticos. UNITERMOS: Exposição internacional. História das exposiçōes, século XIX. Museografia, século XIX. Exposição Universal, Paris, 1889: presença brasileira.

Anais do Museu Paulista, N.Sér. v.4, p.211-61, jan./dez.1996

Brazil goes to Paris in 1889: a place at the Universal Exposition

Heloisa Barbuy

The A. studies the meaning of Brazilian presence in the 1889 Universal Exposition in Paris from a museographical point of view. Based on rich and in large part ignored or underexplored sources, she reveals the efforts made to show Brazil as an attractive country for foreigners and analyzes the allegorical repertoire put into action, along with the rhetorics or different sorts of exhibition, either of natural and manufactured items as well as artistic and scientific in character.

UNITERMS: International exhibition. History of exhibitions, 19th-century. Museography, 19th-century. The Universal Exposition,

Paris, 1889: Brazilian presence.

Anais do Museu Paulista, N.Sér. v.4, p.211-61, jan./dez.1996

História a partir das coisas: tendências recentes nos estudos de cultura material

\section{Marcelo Rede}

Este artigo avalia as idéias de uma publicação coletiva organizada por Lubar e Kingery, History from things. Essays on material culture. Dois problemas são salientados: a formulação de um conceito de cultura que possa abranger os segmentos socialmente apropriados do universo físico e o tratamento metodológico da cultura material como documento histórico.

UNITERMOS: Cultura Material. História e Cultura Material.

Anais do Museu Paılista, N.Sér. v.4, p.265-82, jan./dez.1996

History from things: recent trends in the study of material culture

\section{Marcelo Rede}

This article aims to appraise the ideas of a collective publication edited by Lubar and Kingery, History from things. Essays on material culture. Two problems are put forward: the formulation of a concept of culture that might encompass the socially appropriated segments of the physical universe and the methodological treatments of material culture as historical document.

UNITERMS: Material Culture. History and Material Culture.

Anais do Museu Paulista, N.Sér. v.4, p.265-82, jan./dez.1996 